\title{
PENGARUH BUDAYA ORGANISASI, GAYA KEPEMIMPINAN DAN KECERDASAN EMOSIONAL TERHADAP KOMITMEN ORGANISASI
}

\author{
Hanny Liany \\ Program Studi Magister Manajemen Universitas Tarumanagara \\ hannyliany@gmail.com
}

Masuk : 07-06-2020, revisi : 26-06-2020 diterima untuk diterbitkan : 26-06-2020

\begin{abstract}
The purpose of this research is to examine whether there is an influence between 1) organizational culture 2) leadership style 3) emotional intelligence 4) organizational culture, leadership style and emotional intelligence simultaneously to organizational commitment. Sample was selected using probability sampling method amounted to 129 respondents at Yontomo Sukses Abadi Corporate based in Tangerang. Data processing techniques using classical assumption testing and multiple linear analysis assisted by SPSS program version 25 . The result of this study shows that 1) Organizational culture has a significant effect on organizational commitment 2) Leadership Style has a significant effect on organizational commitment 3) Emotional intelligence does not have a significant effect on organizational commitment 4) Organizational Culture, leadership style and emotional intelligence simultaneously influence organizational commitment.
\end{abstract}

Keywords: Organization Culture, Leadership Behavior, Emotional Intelligence, Organizational Commitment

Abstrak: Tujuan dari penelitian ini adalah untuk menguji apakah terdapat pengaruh antara 1) Budaya Organisasi 2) Gaya Kepemimpinan 3) Kecerdasan Emosional 4) Budaya Organisasi, Gaya Kepemimpinan dan Kecerdasan Emosional secara simultan terhadap komitmen organisasi. Sampel dipilih menggunakan metode probability sampling, sampling berjumlah 129 responden di PT Yontomo Sukses Abadi Tangerang. Teknik pengolahan data menggunakan pengujian asumsi klasik dan analisis linear berganda yang dibantu dengan program SPSS versi 25. Hasil penelitian ini menunjukan bahwa 1) Budaya organisasi berpengaruh secara signifikan terhadap komitmen organisasi 2) Gaya Kepemimpinan berpengaruh secara signifikan terhadap komitmen organisasi 3) Kecerdasan emosional tidak berpengaruh signifikan terhadap komitmen organisasi 4) Budaya Organisasi, Gaya kepemimpinan dan kecerdasan emosional secara simultan berpengaruh terhadap komitmen organisasi.

Kata kunci: Budaya Organisasi (BO), Gaya Kepemimpinan (GK), Kecerdasan Emosional (KE), Komitmen Organisasi (KO)

\section{PENDAHULUAN}

Salah satu sumber daya perusahaan yang memiliki nilai kompetitif adalah sumber daya manusia. Sumber daya manusia merupakan faktor utama dalam suatu organisasi, karena organisasi dibuat berdasarkan berbagai visi, misi dan tujuan untuk kepentingan manusia dan dalam pelaksanaan misinya dikelola dan diurus oleh manusia, sehingga manusia merupakan faktor strategis dalam semua kegiatan organisasi (Larasati, 2018).

Banyak sekali faktor yang harus diperhatikan dalam manajemen sumber daya manusia, baik faktor internal maupun eksternal. PT. Yontomo Sukses Abadi adalah salah satu perusahaan yang terus memperhatikan sumber daya manusia guna untuk mencapai tujuan perusahaan dan dapat bersaing dalam dunia global. Dengan sumber daya manusia dengan baik, perusahaan dapat memecahkan permasalahan-permasalahan. Masalah yang sering dihadapi 
oleh perusahaan mengenai sumber daya manusia salah satunya adalah bagaimana mempertahankan komitmen organisasi terhadap perusahaan.

Komitmen organisasi akan berdampak positif terhadap sikap dan perilaku karyawan dalam mencapai tujuan perusahaan (Yavuz, 2010). Mengenai hal ini dapat dikatakan bahwa komitmen organisasi yaitu adalah tingkat keinginan yang kuat untuk tetap berada dalam organisasi tersebut, keinginan untuk terus berusaha dan bekerja keras sesuai dengan tujuan organisasi, dan hal tersebut sangat penting untuk dimiliki oleh setiap karyawan guna untuk kemajuan perusahaan. Maka dari itu komitmen organisasi merupakan faktor penting yang harus diteliti dalam perusahaan, karena komitmen organisasi akan berpengaruh terhadap sikap dan perilaku karyawan dalam bekerja.

Oleh sebab itu, pihak manajemen perlu mengetahui faktor yang dapat meningkatkan komitmen organisasi. Sehingga penelitian ini bertujuan untuk mengetahui pengaruh 1) Budaya Organisasi 2) Gaya Kepemimpinan 3) Kecerdasan Emosional terhadap komitmen organisasi dan mengetahui pengaruh budaya organisasi, gaya kepemimpinan dan kecerdasan emosional secara simultan terhadap komitmen organisasi.

\section{TELAAH KEPUSTAKAAN \\ Komitmen Organisasi}

Pool and Pool (2007) mengatakan komitmen organisasi mencerminkan sejauh mana seseorang mengidentifikasikan suatu organisasi dan berkomitmen untuk tujuan organisasinya. Jadi dapat disimpulkan bahwa komitmen organisasi berarti bentuk dari perilaku seseorang yang yakin dan bersedia untuk memberikan kesetiaan mereka kepada suatu organisasi.

\section{Budaya Organisasi}

Budaya organisasi umumnya dipandang sebagai seperangkat nilai-nilai kunci, asumsi, pemahaman, dan norma yang dibagikan oleh anggota organisasi dan diajarkan kepada anggota baru atau anggota lainnya (Daft, 2005). Yang berarti dapat disimpulkan nilai-nilai, pemahaman dan norma antara sesama anggota organisasi.

\section{Gaya Kepemimpinan}

Menurut House et al. (2001:494) menjelaskan bahwa kemampuan individu untuk mempengaruhi, memotivasi dan memberikan kontribusi bagi keefekifan orang lain dan kesuksesan organisasi. Dapat disimpulkan bahwa pengaruh yang diberikan pemimpin untuk memotivasi dan memberikan kontribusi bagi organisasi.

\section{Kecerdasan Emosional}

Menurut Nwokah dan Ahiauzu (2009) menyatakan bahwa kecerdasan emosional merupakan dasar dari kualitas personal seperti percaya diri yang realistis, integritas, pengetahuan tentang kelebihan dan kekurangan diri sendiri, ketabahan atau ketangguhan, motivasi diri, ketekunan dan mudah berteman. Yang dapat disimpulkan bahwa dasar akan kualitas personal individu.

\section{Kaitan antar Variabel}

\section{Budaya Organisasi berpengaruh terhadap Komitmen Organisasi}

Yiing and Ahmad (2008), Rahman et al (2018), Park, S. and Doo, M.Y. (2020) menemukan bahwa budaya organisasi secara langsung maupun tidak langsung akan mempengaruhi komitmen organisasi.

H1: Terdapat pengaruh signifikan antara budaya organisasi terhadap komitmen organisasi.

\section{Gaya Kepemimpinan berpengaruh terhadap Komitmen Organisasi}

Kohlmeyer et. al (2014) menyatakan bahwa gaya kepemimpinan mempengaruhi komitmen organisasi baik secara langsung ataupun tidak langsung. Sedangkan menurut Cheok dan Eleanor (2010) dan dari Rahman et. al (2018), komitmen organisasi dan kinerja karyawan secara langsung dipengaruhi oleh gaya kepemimpinan transformational oleh manajer atau pimpinannya.

$\mathrm{H} 2$ : Terdapat pengaruh signifikan antara gaya kepemimpinan terhadap komitmen organisasi 


\section{Kecerdasan Emosional berpengaruh terhadap Komitmen Organisasi}

Naderi (2012), Cheok dan Eleanor (2010) dan Jamshed (2018) menemukan dalam penelitiannya mengenai kecerdasan emosional dan komitmen organisasi, bahwa keduanya memiliki kolerasi yang positif. Dalam penelitiannya, Naderi menjelaskan bahwa sebuah organisasi memerlukan karyawan yang memiliki kecerdasan emosi yang tinggi, karena berpengaruh kepada kinerja mereka.

H3: Terdapat pengaruh signifikan antara kecerdasan emosional terhadap komitmen organisasi. Budaya Organisasi, Gaya Kepemimpinan dan Kecerdasan Emosional berpengaruh secara simultan terhadap Komitmen Organisasi.

Awan et al (2010) mengenai adanya hubungan antara gaya kepemimpinan, budaya organisasi dan komitmen organisasi bagi karyawan perpustakaan di perpustakaan. Al Sada et al (2017) dalam penelitiannya yang bertujuan untuk menentukan jenis budaya organisasi dan gaya kepemimpinan apa yang memiliki dampak terbesar pada motivasi kerja, kepuasan kerja dan komitmen organisasi karyawan di sektor pendidikan Qatar.

H4: Terdapat pengaruh budaya organisasi, gaya kepemimpinan dan kecerdasan emosional secara simultan terhadap komitmen Organisasi

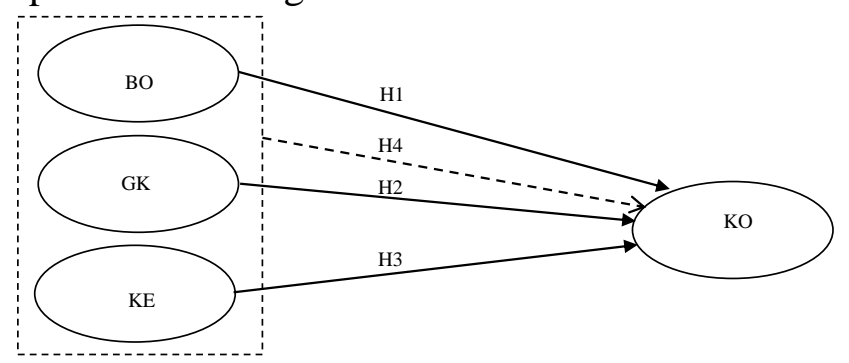

\section{Gambar 1 Model Penelitian}

\section{METODOLOGI PENELITIAN}

Desain penelitian ini adalah penelitian deskriptif dengan metode cross sectional design. Populasi dalam penelitian ini adalah seluruh karyawan PT Yontomo Sukses Abadi Tangerang. Metode pengambilan sampel dalam penelitian ini adalah metode probability sampling yang artinya setiap anggota populasi memiliki kesempatan yang sama untuk terpilih sebagai sampel. Sementara teknik pemilihan sampel yang digunakan dalam penelitian ini adalah simple random sampling dikarenakan peneliti tidak memiliki kriteria khusus dalam penyebaran kuisioner yang akan dibagikan kepada responden. Sampel dalam penelitian ini sebesar 129 orang karyawan PT Yontomo Sukses Abadi. Berdasarkan data yang telah dikumpulkan, diketahui bahwa mayoritas responden berjenis kelamin perempuan yang terbukti dari 129 orang responden, sebesar 71 orang atau sebesar $55 \%$ responden berjenis kelamin perempuan dan sebesar 58 orang atau sebesar 45\% responden berusia 31-40 tahun. Responden pada penelitian ini, sebesar 55 orang atau $43 \%$ memiliki pendidikan terakhir sarjana strata satu dan sebanyak 60 orang atau $47 \%$ memiliki masa kerja 5-8 tahun dalam organisasi tersebut.

Beberapa instrumen diadaptasi dari penelitian terdahulu untuk mengukur variabel penelitian, pengukuran objek penelitian diukur menggunakan skala Likert lima poin dengan 1 menunjukan "sangat tidak setuju" dan 5 menunjukan "sangat setuju". Tabel 1 menunjukan pengukuran masing-masing variabel dan sumbernya, instrumen tersebut telah dilakukan analisis validitas dengan hasil analisis $r$ hitung $>r$ tabel. Sementara untuk analisis reliabilitas didasarkan pada nilai cronbach's alpha dan composite reliability yang masing-masing hasilnya menunjukan nilai lebih dari 0,6 sehingga semua indikator dalam penelitian adalah reliabel (Maholtra, 2010). Pengumpulan data pada penelitian ini dilakukan dengan pembagian kuesioner secara online dengan menggunakan google-form. Metode analisis data dalam penelitian ini menggunakan Uji asumsi klasik dengan bantuan program SPSS versi 25. Taraf signifikansi yang digunakan pada penelitian ini adalah sebesar $5 \%$. 


\section{HASIL UJI STATISTIK}

Hasil pengujian koefisien determinasi $\mathrm{R}^{2}$ dari penelitian ini menunjukan nilai Adjusted $\mathrm{R}$ square (koefisien determinasi) sebesar 0,178, hal ini mengandung arti bahwa pengaruh variabel BO, GK dan KE secara simultan terhadap variabel KO adalah sebesar 17,8\%. Sisanya yaitu sebesar $82.2 \%(100 \%$ - 17.8\%) dijelaskan oleh variabel-variabel di luar penelitian ini. Berdasarkan hasil tersebut, maka koefisien determinasi pada penelitian ini tergolong lemah. Kemudian berdasarkan hasil pengujian Uji T, diketahui bahwa hipotesis 1, 2, 4 dalam penelitian ini dapat diterima, sedangkan hipotesis 3 ditolak.

\section{Tabel 1}

\section{Hasil Pengujian Hipotesis}

Coefficients

\begin{tabular}{|c|c|c|c|c|c|}
\hline \multirow{2}{*}{ Model } & \multicolumn{2}{|c|}{ Unstandardized Coefficients } & \multirow{2}{*}{$\begin{array}{c}\text { Standardized Coefficients } \\
\text { Beta }\end{array}$} & \multirow[t]{2}{*}{$\mathrm{t}$} & \multirow{2}{*}{ Sig. } \\
\hline & B & Std. Error & & & \\
\hline (Constant) & 38.415 & 7.564 & & 5.078 & .000 \\
\hline BO & .219 & .070 & .272 & 3.115 & .002 \\
\hline GK & .537 & .169 & .282 & 3.170 & .002 \\
\hline KE & -.096 & .101 & -.080 & -.948 & .345 \\
\hline
\end{tabular}

a. Dependent Variable: KO *p<0,05;

Berdasarkan Tabel 1. di atas dapat ditarik kesimpulan bahwa variabel Budaya Organisasi Diketahui nilai Sig. untuk pengaruh BO terhadap KO sebesar 0,02<0,05 dan nilai t hitung 3,115 $>\mathrm{t}$ Tabel 1,979, sehingga dapat disimpulkan bahwa $\mathrm{H} 1$ diterima yang berarti terdapat pengaruh yang signifikan antara BO terhadap KO. Kemudian diketahui nilai Sig. untuk pengaruh GK terhadap KO adalah sebesar 0,05 dan nilai t hitung 3,170 > t Tabel 1,979, sehingga dapat disimpulkan bahwa $\mathrm{H} 2$ diterima yang berarti terdapat pengaruh yang signifikan antara GK terhadap KO. Selanjutnya diketahui nilai Sig. untuk pengaruh KE terhadap KO sebesar 0,345>0,05 dan nilai $\mathrm{t}$ hitung -948 < t Tabel 1,979, sehingga dapat disimpulkan bahwa H3 ditolak yang berarti tidak terdapat pengaruh yang signifikan antara KE terhadap KO.

\section{Tabel 2}

\section{Hasil Uji F}

\begin{tabular}{|c|c|c|c|c|c|c|}
\hline \multicolumn{7}{|c|}{ ANOVA $^{a}$} \\
\hline & Model & Sum of Squares & df & Mean Square & $\mathrm{F}$ & Sig. \\
\hline \multirow{3}{*}{1} & Regression & 1650.243 & 3 & 550.081 & 10.229 & $.000^{\mathrm{b}}$ \\
\hline & Residual & 6721.772 & 125 & 53.774 & & \\
\hline & Total & 8372.016 & 128 & & & \\
\hline
\end{tabular}

a. Dependent Variable: KO

b. Predictors: (Constant), BO, GK, KE

Berdasarkan hasil uji $\mathrm{F}$ pada tabel 2 diketahui nilai signifikansi untuk pengaruh $\mathrm{BO}$, GK dan KE secara simultan terhadap KO adalah sebesar 0,000<0,05 dan nilai $\mathrm{F}$ hitung 10,229> F tabel 2,68, sehingga dapat disimpulkan bahwa $\mathrm{H} 4$ diterima yang berarti terdapat pengaruh secara simultan antara BO, GK, KE terhadap KO. Sehingga dapat disimpulkan bahwa H1, H2, H4 diterima, sedangkan $\mathrm{H} 3$ ditolak.

\section{Diskusi}

Hasil pengujian hipotesis pertama menemukan bahwa Budaya Organisasi secara signifikan berpengaruh terhadap Komitmen Organisasi. Hal ini sesuai dengan penelitian Rahman et al (2018) bahwa Budaya organisasi berpengaruh signifikan dan positif terhadap Komitmen Organisasi. Menurut Cameron \& Queen (2006) menyatakan bahwa komitmen karyawan atau kelompok dicapai melalui pengembangan partisipasi karyawan dalam dinamika kerja, proses manajemen serta pengambilan keputusan. Tugas utama dari manajemen adalah mengendalikan dan membina karyawan sehingga memudahkan mereka agar bisa berpartisipasi (Rangkuti, 2015).

Hasil pengujian hipotesis $\mathrm{H} 2$ ditemukan bahwa terdapat pengaruh yang signifikan antara gaya kepemimpinan terhadap komitmen organisasi. Hasil tersebut konsisten dengan hasil penelitian sebelumnya yang menjelaskan bahwa perilaku pemimpinan terhadap karyawan 
mempengaruhi level komitmen setiap karyawan tersebut (Rahman et al, 2018). Sehingga diperlukan pemimpin yang memiliki positive mindset sehingga dapat meningkatkan komitmen organisasi. Sebagai tambahan, melalui penelitian ini penting bagi pemimpin untuk memperhatikan relasi dengan karyawannya, sehingga hal ini dapat memotivasi mereka dalam bekerja dan memiliki level komitmen yang tinggi terhadap organisasi.

Hasil pengujian hipotesis H3 yaitu terdapat pengaruh signifikan antara kecerdasan emosional terhadap komitmen organisasi, tidak diterima atau ditolak. Dalam penelitian ini tidak ditemukan pengaruh signifikan antara kecerdasan emosional terhadap komitmen organisasi. Hal ini tidak sesuai dengan penelitian sebelumnya yang menyatakan bahwa Kecerdasan emosional berpengaruh terhadap komitmen organisasi (Nahid, 2012). Akan tetapi dalam penelitian ini, tidak ditemukan pengaruh. Kemungkinan besar dikarenakan bahwa faktor komitmen organisasi dalam populasi ini sangat mengandalkan gaya kepemimpinan dan budaya organisasi, sehingga pengaruh internal individu menjadi lebih sedikit perannya dibandingkan faktor budaya organisasi dan gaya kepemimpinan tersebut.

Selanjutnya, hasil pengujian untuk hipotesis $\mathrm{H} 4$ yaitu terdapat pengaruh budaya organisasi, gaya kepemimpinan dan kecerdasan emosional secara simultan terhadap komitmen Organisasi, hipotesis ini diterima. Dalam penelitian ini ditemukan bahwa ada pengaruh simultan antara budaya organisasi, gaya kepemimpinan dan kecerdasan emosional terhadap komitmen organisasi dengan presentase $17,8 \%$ yang mana bisa disimpulkan memiliki pengaruh yang tergolong rendah. Karena sisanya yaitu sekitar $82,2 \% \quad(=100-17,8 \%)$ dipengaruhi oleh variabel lain diluar variabel dalam penelitian ini.

\section{KESIMPULAN DAN SARAN}

Hasil penelitian menunjukan bahwa budaya organisasi dan gaya kepemimpinan memberikan pengaruh signifikan terhadap komitmen organisasi, sehingga dapat diberikan saran kepada perusahaan untuk menjaga budaya organisasi yang sudah melekat sehingga nilainilai yang terkandung dalam organisasi tersebut mampu mendorong sesama anggotanya untuk mencapai tujuan organisasi. Peran pemimpin juga sangat penting dalam memberikan pengaruh signifikan terhadap komitmen organisasi. Pemimpin yang mampu memberikan motivasi, arahan dan mempengaruhi anggota tim dapat meningkatkan level komitmen dalam organisasi tersebut, sehingga sangatlah penting bagi pemimpin untuk terus memperbaiki diri dan terus belajar untuk bisa bersama mencapai tujuan organisasi.

Bagi penelitian selanjutnya, dihimbau untuk menggunakan variabel lain yang dapat mempengaruhi komitmen organisasi, karena penelitian ini masih sangat terbatas kepada variabel budaya organisasi, gaya kepemimpinan dan kecerdasan emosional.

\section{Implikasi Manajerial}

Berkaitan dengan hasil penelitian, maka dapat disampaikan beberapa implikasi manajerial yang dapat diterapkan oleh perusahaan. Melihat dari hasil penelitian yang mengungkapkan pengaruh budaya organisasi dan gaya kepemimpinan menjadi faktor penting untuk bisa mengembangkan komitmen karyawan. Perusahaan harus bisa menciptakan budaya yang mendukung dan memiliki gaya kepemimpinan yang memberikan arahan dan motivasi kepada karyawannya. Gaya kepemimpinan yang baik yaitu terus menciptakan sistem perusahaan yang baik dan penguatan komitmen organisasi sehingga dapat mencapai tujuan organisasi.

\section{DAFTAR RUJUKAN/PUSTAKA}

Al-Sada, M., Al-Esmael, B. \& Faisal, M. (2017). Influence of organizational culture and leadership style on employee satisfaction, commitment and motivation in the educational sector in Qatar. EuroMed Journal of Business, 12(2), 163-188. 
Dasborough, M. (2019). Emotional intelligence as a moderator of emotional responses to leadership. Emotions and Leadership (Research on Emotion in Organizations, 15), Emerald Publishing Limited, 69-88.

Ghozali, I. (2011). Aplikasi Analisis Multivariate dengan Program SPSS. Semarang: Badan Penerbit Universitas Diponegoro.

Huey Yiing, L. \& Zaman Bin Ahmad, K. (2009). The moderating effects of organizational culture on the relationships between leadership behaviour and organizational commitment and between organizational commitment and job satisfaction and performance. Leadership \& Organization Development Journal, 30(1), 53-86.

Islam, T., Tariq, J., \& Usman, B. (2018). Transformational leadership and four-dimensional commitment: Mediating role of job characteristics and moderating role of participative and directive leadership styles. Journal of Management Development, 37(9/10), 666-683.

Keskes, I., Sallan, J. M., Simo, P., \& Fernandez, V. (2018). Transformational leadership and organizational commitment: Mediating role of leader-member exchange. Journal of Management Development, 37(3), 271-284.

Khalid, J., Khaleel, M., Ali, A., \& Islam, M. (2018). Multiple dimensions of emotional intelligence and their impacts on organizational commitment and job performance. International Journal of Ethics and Systems, 34(2), 221-232.

Kohlmeyer III, J. M., Mahenthiran, S., Parker, R. J., \& Sincich, T. (2014). Leadership, budget participation, budgetary fairness, and organizational commitment. Advances in Accounting Behavioral Research. Published online: 07 Oct 2014; 95-118.

Lam, C. S., Eleanor, R. E., \& O'Higgins. (2012). Enhancing employee outcomes: The interrelated influences of managers' emotional intelligence and leadership style. Leadership \& Organization Development Journal, 33(2), 149-174.

Larasati, S. (2018). Manajemen Sumber Daya Manusia. Yogyakarta: Deepublish

Limpanitgul, T., Boonchoo, P., Kulviseachana, S., \& Photiyarach, S. (2017). The relationship between empowerment and the three-component model of organisational commitment: an empirical study of Thai employees working in Thai and American airlines. International Journal of Culture, Tourism and Hospitality Research, 11(2), 227-242.

Malhotra, N. K. (2010). Marketing Research: An Applied Orientation. Boston: Pearson.

Marnis, P. (2008). Manajemen Sumber Daya Manusia. Sidoarjo: Zifatama Publisher.

Mesu, J., Sanders, K., \& Riemsdijk, M. (2015). Transformational leadership and organisational commitment in manufacturing and service small to medium-sized enterprises: The moderating effects of directive and participative leadership. Personnel Review, 44(6), 970-990.

Mwesigwa, R., Tusiime, I., \& Ssekiziyivu, B. (2020). Leadership styles, job satisfaction and organizational commitment among academic staff in public universities. Journal of Management Development, 39(2), 253-268.

Naderi Anari, N. (2012). Teachers: emotional intelligence, job satisfaction, and organizational commitment. Journal of Workplace Learning, 24(4), 256-269.

Raharjo, K., Nurjannah, Solimun, \& Fernandes, A. A. J. (2018). The influence of organizational culture and job design on job commitment and human resource performance. Journal of Organizational Change Management, 31(7), 1346-1367.

Rahman, S., Islam, M. Z., Abdullah, A. D. A., Sumardi, W. A. (2018). Empirical investigation of the relationship between organizational factors and organizational commitment in service organizations. Journal of Strategy and Management.

Rangkuti, F. (2015). SWOT Balanced Scorecard-Teknik Menyusun Strategi Korporat yang Efektif plus Cara Mengelola Kinerja dan Risiko. Jakarta: PT Gramedia Pustaka Utama 